\title{
Study on Doppler Findings and Neonatal Outcome in Fetal Growth Restriction: A Teaching Hospital Based Study
}

\author{
Kiran Kumar Neelapu ${ }^{1}$ \\ ${ }^{1}$ Assistant Professor, Department of Radiology, Nimra Institute of Medical Sciences, Nimra Nagar, Ibrahimpatnam, Jupudi, Vijayawada.
}

\begin{abstract}
Background: Intrauterine growth restriction (IUGR) is defined as sonographic estimated fetal weight <10th percentile for gestational age. Intrauterine growth retardation (IUGR) is associated with an increased risk of perinatal mortality, morbidity, and impaired neurodevelopment. Subjects and Methods: A total of 65 women with singleton pregnancies of 28 weeks and above, who were diagnosed with fetal growth restriction and were evaluated by Doppler studies according to inclusion and exclusion criteria. Results: On analysing the antenatal Doppler studies, abnormal CP ratio, elevated umbilical artery PI and reduced MCA PI were found in 12, 16 and 32 fetuses respectively. CP ratio showed a sensitivity of $19.61 \%$ and specificity of $85.71 \%$ with a positive predictive value of $83.33 \%$ and negative predictive value of 22.64 $\%$. Pulsatility index of umbilical artery showed sensitivity of $23.53 \%$ and specificity of $71.43 \%$, with Positive predictive value of $75.00 \%$ and Negative predictive value of $20.41 \%$. Pulsatility index of MCA showed a sensitivity of $52.94 \%$ and specificity of $64.29 \%$ with PPV of $84.38 \%$ and NPV of $27.27 \%$. Conclusion: The IUGR is an important cause of perinatal morbidity and mortality. Antenatal Doppler analysis of UA and MCA can predict neonatal outcome in FGR foetuses. The fetal growth restriction has considerable perinatal and long term effects on the neonate. Once it is suspected careful Doppler evaluation can identify fetuses at risk for poor neonatal outcome.
\end{abstract}

Keywords: Doppler Finding Tests, Neonatal and FGR.

Corresponding Author: Dr Kiran kumar Neelapu, Assistant Professor, Department of Radiology, Nimra Institute of Medical Sciences, Nimra Nagar, Ibrahimpatnam, Jupudi, Vijayawada, krishna District, Andhra Pradesh-521456

Received: November 2018

Accepted: December 2018

\section{Introduction}

Intrauterine growth restriction (IUGR) is defined as sonographic estimated fetal weight <10th percentile for gestational age. ${ }^{[1]}$ According to the American College of Obstetricians and Gynecologists, IUGRis "one of the most common and complex problems in modern obstetrics." ${ }^{[2]}$ This characterization is understandable considering the various published definitions, poor detection rate, limited preventive or treatment options, multiple associated morbidities, and increased likelihood of perinatal mortality associated with IUGR. Suboptimal growth at birth is linked with impaired intellectual performance and diseases such as hypertension and obesity in adulthood. ${ }^{[2]}$ Fetal growth restriction (FGR) refers to a fetus that has failed to achieve its genetically determined growth potential and affects up to 5-10\% of pregnancies. The World Health Organization defines SGA as a neonatal weight of less than 2500 grams at term. SGA pregnancies often exhibit normal fetal Doppler, while FGR due to placental disease exhibits characteristic maternal and fetal Doppler abnormalities. Doppler studies are non-invasive and help to identify the degree of placental insufficiency and also to detect worsening of the situation, there by decision to intervene can be taken once the need arises. It has been reported that elevated S/D ratio in the umbilical artery can lead to poorer neonatal outcomes even in the absence of
FGR. ${ }^{[3]}$ Increased adverse reactions in short term and long term development has been observed in FGR fetuses when compared with SGA foetuses. ${ }^{[4,5]}$ Hence it can be said that Doppler studies provide a valuable insight into the intrauterine environment. The vessels that are evaluated in obstetric Doppler assessment to monitor FGR are uterine artery, umbilical artery, middle cerebral artery and ductus venosus. Most of the studies have shown that umbilical and middle cerebral artery pulsatility index values are better predictors of fetal outcome. Ductus venosus impairment signifies impending fetal compromise like intra-uterine fetal demise and has a high rate of perinatal mortality. The sequential pattern of flow abnormalities in UA, MCA and DV in that order has been observed in several studies and it has been observed that the UA and MCA are better tools for monitoring fetal well-being and to predict fetal-neonatal outcome in upto $88 \%$ of the cases. ${ }^{[6]}$ The cerebro-placental ratio is obtained by dividing MCA PI by UA PI. It is found to be a better predictor of perinatal outcome than MCA PI or UA PI alone. ${ }^{[7]}$ Aim of this present study was to be the doppler findings tests and neonatal outcome in fetal growth restriction.

\section{Subjects and Methods}

This present study was carried out in the Department of 
Radiology, Nimra Institute of Medical Sciences in collaboration with the Department of Obstetrics and Gynecology during the period from July 2017 to October 2018. A total of 65 women with singleton pregnancies of 28 weeks and above, who were diagnosed with fetal growth restriction and were evaluated by Doppler studies according to inclusion and exclusion criteria. These women and their respective neonates were followed up until discharge from hospital. Once FGR was diagnosed in the antenatal period, the women underwent Doppler studies of maternal uterine artery and fetal umbilical and middle cerebral arteries. Repeat ultrasonography and Doppler were done as necessary and antenatal steroid administration was given to women under 34 weeks' gestational age. The antenatal Doppler evaluation results were compared with neonatal outcome like NICU admissions, length of NICU stay, and need of ventilator, CPAP and complications to the neonates. The predictive value of Doppler evaluation and NICU admission was analysed. Also, antenatal Doppler findings and neonatal outcomes were compared according to gestational age at delivery. The length of NICU stay was used to assess the neonatal morbidity. NICU stay of $<5$ days, 6-10 days and $>10$ days corresponded to mild, moderate and severe neonatal morbidity respectively. The influence of gestational age on the length of NICU stay was studicd. These data collected from the study will be analyzed using sensitivities, specificity and predictive value.

\section{Results}

Table 1: Demographic characteristics of Maternal and neonatal

\begin{tabular}{|c|c|c|}
\hline \multicolumn{2}{|c|}{ Parameters } & No. Of Cases (\%) \\
\hline \multirow{2}{*}{ Age } & $<20$ & $7(10.8)$ \\
\cline { 2 - 3 } & $20-30$ & 58 \\
\hline \multirow{2}{*}{ Co-morbidities } & HTN & $33(50.8)$ \\
\cline { 2 - 3 } & GDM & $0(0.0)$ \\
\hline \multirow{2}{*}{ Mode of Delivary } & Vaginal & $9(13.8)$ \\
\cline { 2 - 3 } & LSCS & $56(86.15)$ \\
\hline \multirow{3}{*}{$\begin{array}{c}\text { Gestational age at } \\
\text { delivery }\end{array}$} & $>37$ week & $36(55.4)$ \\
\cline { 2 - 3 } & $34-37$ week & $18(27.7)$ \\
\cline { 2 - 3 } & $<34$ week & $11(16.9)$ \\
\cline { 2 - 3 } Birth weight & $1.5-2.5 \mathrm{~kg}$ & $61(93.8)$ \\
\hline NICU admissions & $<1.5 \mathrm{~kg}$ & $4(6.15)$ \\
\cline { 2 - 3 } & $>37$ week & $22(43.13)$ \\
\cline { 2 - 3 } & $34-37$ week & $20(39.2)$ \\
\cline { 2 - 3 } & $<34$ week & $09(17.6)$ \\
\cline { 2 - 3 } & Ventilator & $1(1.96)$ \\
\cline { 2 - 3 } & CPAP & $8(15.7)$ \\
\cline { 2 - 3 } & Oxygen support & $42(82.3)$ \\
\hline
\end{tabular}

This present study was carried out on 65 women with singleton pregnancies of 28 weeks and above, who were diagnosed with fetal growth restriction and were evaluated by Doppler studies according to inclusion and exclusion criteria. Out of these, 36 patients $(55.4 \%)$ delivered at term, 18 patients delivered between 34-37 weeks of gestation and 11 patients delivered before 34 weeks. On analysing the antenatal Doppler studies, abnormal CP ratio, elevated umbilical artery PI and reduced MCA PI were found in 12, 16 and 32 fetuses respectively [Figure 2].

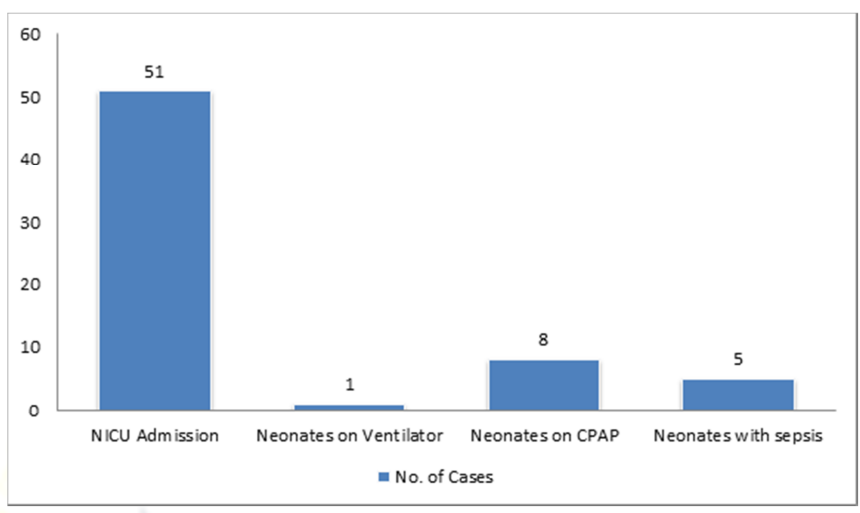

Figure 1: Neonatal outcomes

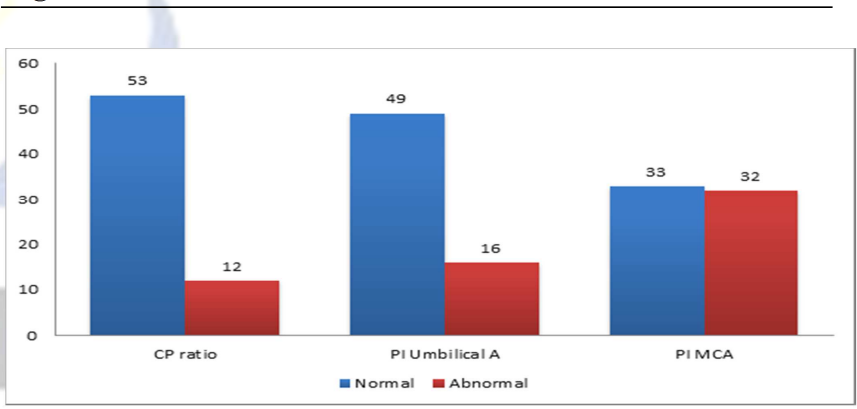

Figure 2: Doppler variables studied.

In [Table 2], the CP ratio showed a sensitivity of $19.61 \%$ and specificity of $85.71 \%$ with a positive predictive value of $83.33 \%$ and negative predictive value of $22.64 \%$. Pulsatility index of umbilical artery showed sensitivity of $23.53 \%$ and specificity of $71.43 \%$, with Positive predictive value of $75.00 \%$ and Negative predictive value of $20.41 \%$. Pulsatility index of MCA showed a sensitivity of $52.94 \%$ and specificity of $64.29 \%$ with PPV of $84.38 \%$ and NPV of $27.27 \%$.

Table 2: Doppler in predicting NICU

\begin{tabular}{|c|c|c|c|c|c|c|c|}
\hline \multicolumn{3}{|c|}{ Doppler variables } & \multirow{2}{*}{$\begin{array}{c}\text { Sensitivity } \\
19.61\end{array}$} & \multirow{2}{*}{$\begin{array}{c}\text { Specificity } \\
85.71\end{array}$} & \multirow{2}{*}{$\begin{array}{c}\begin{array}{c}\text { Positive } \\
\text { predictive value }\end{array} \\
83.33\end{array}$} & \multirow{3}{*}{$\begin{array}{c}\begin{array}{c}\text { Negative } \\
\text { predictive value }\end{array} \\
22.64\end{array}$} & \multirow{2}{*}{$\begin{array}{c}\text { Accuracy } \\
33.85\end{array}$} \\
\hline CP ratio & 10 (TP) & $02(\mathrm{FP})$ & & & & & \\
\hline & $41(\mathrm{FN})$ & $12(\mathrm{TN})$ & & & & & \\
\hline \multirow[t]{2}{*}{ PI umbilical A } & $12(\mathrm{TP})$ & $04(\mathrm{FP})$ & \multirow[t]{2}{*}{23.53} & \multirow[t]{2}{*}{71.43} & \multirow[t]{2}{*}{75.00} & \multirow[t]{2}{*}{20.41} & \multirow[t]{2}{*}{33.85} \\
\hline & $39(\mathrm{FN})$ & $10(\mathrm{TN})$ & & & & & \\
\hline \multirow[t]{2}{*}{ PI MCA } & $27(\mathrm{TP})$ & $05(\mathrm{FP})$ & \multirow[t]{2}{*}{52.94} & \multirow[t]{2}{*}{64.29} & \multirow[t]{2}{*}{84.38} & \multirow[t]{2}{*}{27.27} & \multirow[t]{2}{*}{55.38} \\
\hline & $24(\mathrm{FN})$ & 09(TN) & & & & & \\
\hline
\end{tabular}


sequalae as depression and suicide. Fetal growth restriction affects $5-10 \%$ of pregnancies. ${ }^{[8]}$ Fetal growth restriction is a common condition seen during antenatal surveillance, with significant perinatal complications. Apart from fetal biometry, Doppler evaluation of uterine artery, umbilical artery, middle cerebral artery and ductus venosus are important antenatal surveillance tools and prognosticators as seen in several studies. Umbilical artery identifies increased placental resistance by an increased PI value. Absent or reversed flow in the umbilical artery appears after $>50 \%$ of placental vessels are obliterated. ${ }^{[6]}$ Studies have shown that monitoring of FGR fetuses by umbilical artery Doppler improves neonatal outcomes. ${ }^{[9]}$ The middle cerebral artery normally has a high resistance flow. A low PI of MCA indicates brain sparing effect. However, at a later stage of FGR, false normalization of MCA PI may indicate failing fetal circulation. Cerebral placental ratio (CP ratio) is obtained by dividing MCA PI by UA PI. A value $<1$ is abnormal. Studies have shown that it is a better predictor of adverse perinatal outcome compared to MCA PI or UA PI alone. ${ }^{[10]}$ In the current study, sensitivity in predicting NICU admission for UA PI was $23.53 \%$, MCA PI was $52.94 \%$ and CP ratio was $19.61 \%$. The specificity in predicting NICU admission for UA was $71.43 \%$, MCA was $64.29 \%$ and $\mathrm{CP}$ ratio was $85.71 \%$. In a study by Dhand $\mathrm{H}$ et al, the predictive value for Doppler for detecting abnormal fetal outcome, the sensitivity for UA PI and MCA PI was $44 \%, 71 \%$ respectively and specificity was $61.5 \%$ and $92 \%$ respectively. ${ }^{[1]}$ In another study by Mishra D et al, the predictive value of Doppler in perinatal outcome showed the sensitivity of UA PI, MCA PI and CP ratio to be $53 \%$, $43 \%$ and $86 \%$ respectively and the specificity to be $82 \%$, $80 \%$ and $92 \% .{ }^{[12]}$ In the present study, the positive predictive value for UA PI, MCA PI and CP ratio was 75, 84.38 and 83.33 respectively. The negative predictive value for the same was 20.41, 27.27 and 22.64 respectively. In the study by Dhand $\mathrm{H}$ et al mentioned above, the PPV for predicting fetal outcome for UA PI and MCA PI was $83 \%$ and $94 \%$ and NPV was $20 \%$ and $65 \%$ respectively. Current challenges in the clinical management of IUGR include accurate diagnosis of the truly growth-restricted fetus, selection of appropriate fetal surveillance, and optimizing the timing of delivery. ${ }^{[13-15]}$

\section{Conclusion}

These findings suggest that the IUGR is an important cause of perinatal morbidity and mortality. Antenatal Doppler analysis of UA and MCA can predict neonatal outcome in FGR foetuses. The fetal growth restriction has considerable perinatal and long term effects on the neonate. Once it is suspected careful Doppler evaluation can identify fetuses at risk for poor neonatal outcome. Significant advances have been made in the understanding of the complex etiology and pathophysiology of FGR. This knowledge will certainly aid the clinician to optimize antepartum monitoring and time delivery of FGR infants.

\section{References}

1. Battaglia FC, Lubchenko LO. A practical classification of newborn infants by weight and gestational age. J Pediatr 1967;71:159-63. Level II-3.

2. American College of Obstetricians and Gynecologists. Intrauterine growth restriction; ACOG practice bulletin no. 12. Washington, DC: ACOG; 2000. Level III.

3. Filmar G, Panagopoulos G, Minior V, Barnhard Y, Divon MY Elevated umbilical artery systolic/diastolic ratio in the absence of fetal growth restriction. Arch Gynecol Obstet. 2013;288(2):279-85.

4. Von Beckerath AK, Kollmann M, Rotky-Fast C, Karpf E, Lang U, Klaritsch P. Perinatal complications and long term neurodevelopmental outcome of infants with intrauterine growth restriction. Am J Obstet Gynecol. 2013;208(2):130.

5. Roy A, Mukherjee S, Bhattacharyya SK, Banerjee P, Das B, Patra KK. Perintal outcome in pregnancies with intra-uterine growth restriction by using umbilical and middle cerebral artery colour Doppler. Indian Med Assoc. 2012;110(3):154-7,163.

6. Unterscheider J, Daly S, Geary MP, Kennelly MM, Mc Auliffe FM, O'Donoghue K et al. Predictable progressive Doppler deterioration in IUGR: does it really exist? Am J Obstet Gynecol. 2013;209(6):539.

7. Bano S, Chaudhary V, Pande S, Mehta VL, Sharma AK. Color doppler evaluation of cerebral-umbilical pulsatility ratio and its usefulness in the diagnosis of intrauterine growth retardation and prediction of adverse perinatal outcome. Indian J Radiol Imag. 2010;20(1):20-5.

8. Bam J, Abido A. Diagnosis and management of fetal growth restriction J Preg;2011: 1-5.

9. Figueras F, Gardosi J. Intrauterine growth restriction: new concepts in antenatal surveillance, diagnosis and management. Review Article. Am J Obstet Gynecol. 2011;204(4):288-300.

10. Gupta BD, Sharma R, Shah K. Prediction of IUGR and adverse perinatal outcome by colour Doppler examination of UA PI and MCA:UA PI Ratio. Int J Contemp Med Res. 2016; 3(4):976-8.

11. Dhand H, Kansal K, Dave A. Middle cerebral artery doppler indices better predictor for fetal outcome in IUGR. J Obstet Gynecol India. 2011;61(2):166-71.

12. Mishra D, Sakhi P, Saraf A, Gupta A, Soni K, Dhruw S. Role of obstetric Doppler in prediction of adverse perinatal outcome in intrauterine growth retardation and pregnancy induced hypertension. Sch J App Med Sci. 20131(6):1016-20.

13. Baschat AA. Arterial and venous Doppler in the diagnosis and management of early onset fetal growth restriction. Early Hum Dev 2005; 81:877-87. Level III.

14. Baschat AA, Gembruch U, Reiss I, Gortner L, Weiner CP, Harman CR. Relationship between arterial and venous Doppler and perinatal outcome in fetal growth restriction. Ultrasound Obstet Gynecol 2000;16:407-13. Level II-2.

15. Bilardo CM, Wolf $\mathrm{H}$, Stigter $\mathrm{RH}$, et al. Relationship between monitoring parameters and perinatal outcome in severe, early intrauterine growth restriction. Ultrasound Obstet Gynecol 2004;23:119-25. Level II-1.

Copyright: ( $\odot$ the author(s), publisher. Asian Journal of Medical Radiological Research is an Official Publication of "Society for Health Care \& Research Development". It is an open-access article distributed under the terms of the Creative Commons Attribution Non-Commercial License, which permits unrestricted non-commercial use, distribution, and reproduction in any medium, provided the original work is properly cited.

How to cite this article: Neelapu KK. Study on Doppler Findings and Neonatal Outcome in Fetal Growth Restriction: A Teaching Hospital Based Study. Asian J. Med. Radiol. Res. 2018;6(2):20-22.

DOI: dx.doi.org/10.21276/ajmrr.2018.6.2.6

Source of Support: Nil, Conflict of Interest: None declared. 